Vol 2 (2) 2020, 45-51

\title{
Modifikasi Alat Penakar Curah Hujan Tipe Observatorium (OBS) Guna Validasi dan Efektivitas Pengukuran
}

\author{
Abidin', Erman, Tri Widodo \\ 1Politeknik Negeri Lampung, Bandar Lampung, email: abidinlampung123@gmail.com
}

Submisi : 17 Agustus 2019; Penerimaan : 27 Maret 2020

\begin{abstract}
ABSTRAK
Stasiun Klimatologi Politeknik Negeri Lampung dilengkapi dengan alat penakar curah hujan tipe Observatorium (OBS). Penakar curah hujan yang berfungsi untuk mengukur jumlah curah hujan yang jatuh pada permukaan tanah. Curah hujan yang tercurah masuk dalam corong penakar dan terkumpul di dalam tabung penampung. Pengamatan dilakukan dengan menggunakan gelas ukur, dengan cara mengangkat corong penakar, lalu mengambil tabung penampung curah hujan dan menuangkannya ke dalam gelas ukur. Apabila curah hujan melebihi kapasitas gelas ukur, maka pengukuran dilakukan beberapa kali sehingga curah hujan yang tertampung dapat diukur semua. Hal ini memakan waktu yang lama, sehingga curah hujan sering tumpah pada saat pengukuran, dan hasil pengukuran tidak valid. Permasalahan ini menuangkan suatu gagasan untuk memodifikasi alat penakar curah hujan tipe OBS dengan menggunakan kran. Dengan tujuan pada proses pengukuran menghasilkan data yang valid dan efektif. Penelitian ini menggunakan metode eksprimental membandingkan hasil pengukuran penakar curah hujan yang sudah dimodifikasi dengan yang belum dimodifikasi. Analisis data menggunakan metode kuntitatif dan skala rasio. Pengujian dilakukan sebanyak tiga kali ulangan dengan volume curah hujan yang bervariasi yaitu curah hujan $10 \mathrm{~mm}, 25 \mathrm{~mm}$, dan $50 \mathrm{~mm}$. Dari ketiga kali pengujian dihasilkan rata-rata waktu pengukuran curah hujan dengan menggunakan penakar curah hujan tipe OBS sebelum dimodifikasi, untuk volume curah hujan $10 \mathrm{~mm}=110$ detik, $25 \mathrm{~mm}=243$ detik, $50 \mathrm{~mm}=431$ detik. Hasil pengujian penakar curah hujan tipe OBS hasil modifikasi untuk volume curah hujan $10 \mathrm{~mm}=68$ detik, $25 \mathrm{~mm}=135$ detik, dan $50 \mathrm{~mm}=268$ detik. Disimpulkan bahwa hasil pengukuran curah hujan menggunakan penakar curah hujan tipe OBS yang sudah dimodifikasi dengan tambahan kran lebih valid dan efektif.
\end{abstract}

Kata Kunci: efektif; penakar curah hujan tipe observatorium; valid.

\section{PENDAHULUAN}

\section{Latar belakang masalah}

Stasiun Klimatologi Politeknik
Negeri Lampung merupakan
laboratorium terbuka, dimana tempat berlangsungnya Tri Dharma Perguruan tinggi, salah satunya adalah pendidikan/praktikum. Hampir semua kegiatan praktikum yang disiplin ilmu membidangi pertanian harus menguasai dan mempelajari Klimatologi pertanian. Secara garis besar alat-alat klimatologi dikelompokan menjadi dua yaitu alat manual dan alat otomatis. Alat manual adalah alat yang tidak mempunyai perekam hasil pengukuran. Jadi semua pengamatan dicatat secara manual oleh pengamat. Alat otomatis adalah alat yang mempunyai perekam, dan hasil pengukuran direkam dalam kertas pias, (BPP Klimatologi Pertanian, 2010). Ada beberapa macam alat yang digunakaan pada stasiun klimatologi antara lain: Pengukuran radiasi surya meliputi lama penyinaran yang diukur dengan alat Campbell Stokes, intensitas radiasi diukur dengan alat Aktinograf Dwi 
Logam. Penguapan diukur dengan alat Atmometer Piche dan Panci Evaporasi kelas A. Curah hujan diukur dengan penakar curah hujan tipe Observatorium dan tipe Hellman, dan seterusnya. (BPP Klimatologi Pertanian, 2010). Stasiun Klimatologi Politeknik Negeri Lampung dilengkapi dengan alat penakar curah hujan tipe Observatorium yang tidak menggunakan kran, sehingga penakaran curah hujan memakan waktu yang lama. Penakar hujan OBS berfungsi untuk mengukur jumlah curah hujan yang jatuh pada permukaan tanah dalam periode waktu 24 jam. Pada saat terjadi hujan, curah hujan yang tercurah masuk ke dalam corong penakar. Curah hujan yang masuk dalam penakar dialirkan dan terkumpul di dalam tabung penampung. Pada saat pengamatan curah hujan yang tertampung diukur dengan menggunakan gelas ukur dengan cara mengangkat corong penakar, lalu mengambil tabung penampung curah hujan dan menuangkannya ke dalam gelas ukur. Apabila jumlah curah hujan yang tertampung jumlahnya melebihi kapasitas gelas ukur, maka pengukuran dilakukan berulang kali sehingga curah hujan yang tertampung dapat terukur semua. Hal ini memakan waktu yang cukup lama dan terkadang saat memasukkan curah hujan dari tabung ke gelas ukur sering tumpah, yang mengakibatkan hasil pengukuran kurang valid dan efektif.

\section{Tujuan penelitian}

Tujuan yang ingin dicapai pada penelitian ini adalah sebagai berikut:

1. Memodifikasi alat penakar curah hujan tipe Observatorium (OBS). Dengan cara menambah kran, dengan harapan saat menakar curah hujan cukup membuka kran saja.

2. Mengoptimalkan waktu penakaran curah hujan.
3. Menggunakan bahan dan alat yang efektif dan valid.

\section{METODE PENELITIAN}

\section{Waktu dan lokasi penelitian}

Penelitian direncanakan dilakukan selama enam bulan yaitu bulan April 2018 sampai bulan Oktober 2018 yang kegiatannya dibagi menjadi tiga tahap. Tahap pertama perancangan alat, tahap kedua pembuatan alat dilakukan di Laboratorium Logam dan Otomotif, tahap ketiga pengujian dan penyelesaian data di Stasiun Klimatologi Politeknik Negeri Lampung. Pertimbangan-pertimbangan yang dijadikan dasar penentuan lokasi adalah Laboratorium Logam/Otomotif dan Stasiun Klimatologi Politeknik Negeri Lampung.

\section{Alat dan bahan}

Adapun alat yang digunakan pada penelitian ini adalah sebagai berikut mesin las,mesin milling, mesin gerinda portable, mesin roolplate, mesin gergaji, solder, gunting plat besi, palu. Bahan dasar yang digunakan untuk membuat alat adalah almunium (Al), sedangkan bahan pendukung terdiri dari: Pipa $\varnothing 3 "$, Plat almunium tebal $2 \mathrm{~mm}$, Kran $3 / 4 "$, Timah solder, Kawat las Rb 26 .

\section{Metode desain penelitian}

Metode yang di pakai adalah metode eksperimental, untuk membandingkan hasil pengukuran menggunakan alat pengukur curah hujan tipe observatorium yang sudah di modivikasi dengan yang belum di modivikasi.

\section{Metode pengumpulan data}

Data yang dikumpulkan merupakan data sekunder dan primer. Data sekunder adalah data yang di peroleh secara tidak langsung, yaitu dengan cara mengutip atau mencatat 
dokumen-dokumen yang berupa data statistik, arsip, dan gambar di Stasiun Klimatologi Politeknik Negeri Lampung ataupun sumber lain yang valid dan terkait, serta data-data yang menunjang penelitian ini. Untuk mendukung keberadaan data sekunder, penulis juga menghimpun data primer. Data primer adalah data yang di peroleh langsung dari sumbernya atau pun kondisi real yang didapat langsung di lokasi penelitian dengan cara melakukan Eksprimen dan Dokumentasi.

\section{Teknik eksperimen}

Metode mengumpulkan data atau informasi dalam suatu kondisi dua karekteristik penting dari suatu eksprimen adalah:

a. Adanya perlakuan (treatment) membandingkan antara alat penakar curah hujan tipe Observatorium (OBS) yang sudah dimodifikasi dengan dan yang belum dengan mencatat waktu penakaran.

b. Subyek penelitian yang akan diberi perlakuan khusus.

\section{Teknik dokumentasi}

Teknik dokumentasi merupakan pengamatan gejala objek yang diteliti dengan mengutip dan meneliti dokumen yang tersedia. Pengertian dokumentasi merupakan laporan tertulis dari suatu peristiwa, yang isinya terdiri atas penjelasan dan pemikiran terhadap peristiwa. Dengan rumusan kita dapat memasukkan notulen rapat, laporan panitia kerja, artikel, majalah, iklan dan lain sebagainya kedalam dokumen (Surachmad, 2012).

\section{Analisis data}

Data dianalisis menggunakan metode kuantitatif, kegiatan analisis di lakukan menggunakan skala Rasio. Contoh variabel yang sesuai untuk diukur dengan skala rasio adalah: jarak, waktu, berat, dll (Durri Andriani. Dkk, 2010).

\section{Prosedur Perancangan dan \\ Pembuatan Alat \\ 1.Prosedur Perancangan Alat \\ Secara umum ada beberapa langkah yang harus dilakukan dalam perancangan alat \\ i.Study Literatur}

Dalam study literatur dilakukan pencarian informasi mengenai segala sesuatu yang berhubungan dengan penelitian ini, diantaranya adalah:

a. Melalui sumber buku pustaka.

b. Referensi lainnya yang dianggap valid, misalnya internet.

\section{ii.Penentuan sepesifikasi rancangaan alat}

Secara umum spesifikasi rancangan alat akan disesuaikan dengan alat penakar curah hujan tipe Observatorium (OBS). Di lokasi Stasiun Klimatologi Politeknik Negeri Lampung.

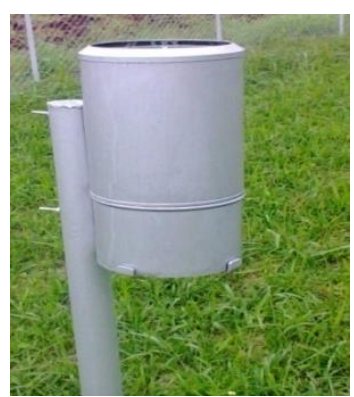

Gambar 1. Kondisi alat penakar curah hujan tipe Observatorium (OBS) di lokasi stasiun klimatologi Politeknik Negeri Lampung

\section{Prosedur Pembuat Alat}

\section{i.Pembuatan corong dan tabung penakar curah hujan tipe observatorium}

Plate di rool menggunakan mesin rool, ukuran/dimensi disesuaikan dengan alat yang ada dengan alat penakar curah hujan pada stasiun 
klimatologi Politeknik Negeri Lampung.

ii.Pemasangan Kran pada Tabung

Tabung di bagian dasar dilubangi guna pemasangan kran posisi samping tabung, kemudian langkah pengelasan kran dengan tabung.

iii.Pemasangan tiang alat dilokasi stasiun klimatologi

Tiang menggunakan pipa dengan $\varnothing$ 2" ditanam kira-kira kedalam $50 \mathrm{~cm}$ kemudian dicor dengan media semen, batu, pasir.

\section{iv.Alat penakar curah hujan}

Siap dipasang pada tiang yang sudah di persiapkan dilokasi stasiun klimatologi

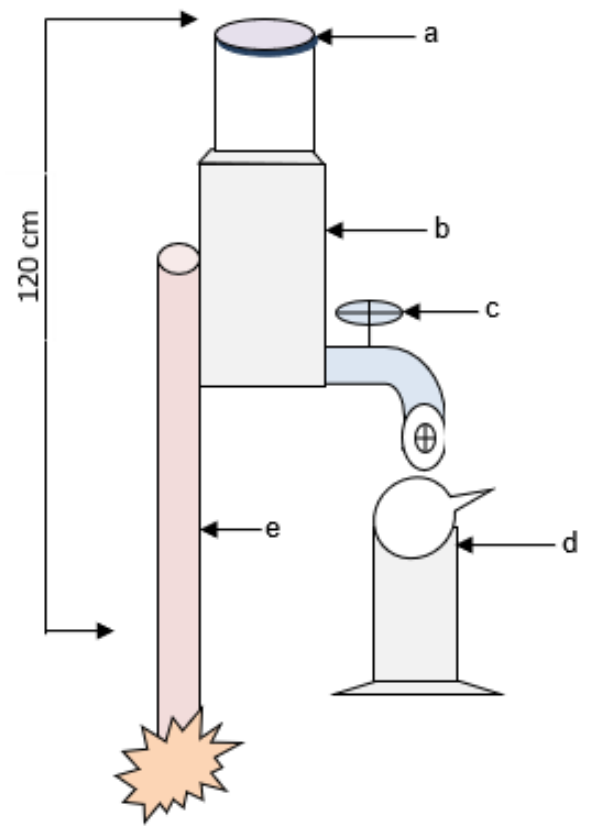

Keterangan:

a.Corong/mulut penakar $(D=16 \mathrm{~cm})$ b.Tabung/sankolektor curah hujan c.Kran

d.Gelas ukur dengan satuan $\mathrm{mm}$ e. Tiang Penyangga

Gambar 2. Perancangan Alat penakar Curah hujan tipe Observatorium yang akan dimofikasi, dimensi menyesuaikan alat yang ada di Stasiun Klimatologi Politeknik Negeri Lampung
Pengujian Alat

1.Prosedur Pengujian fungsi alat

Sebelum digunakan untuk penakar curah hujan dilakukkan pengujian kemungkinan ada kebocoran pada proses pengelasan/penyambungan dan dipastikan air akan habis didalam tabung setelah kran dibuka, dengan cara mengisi air pada tabung.

2.Pengujian Penakar curah hujan tipe Observatorium yang sudah dimodifikasi

Pengukuran ini memiliki tujuan untuk mengetahui waktu yang digunakan untuk menakar curah hujan menggunakan gelas ukur dan mencatat waktu sebanyak tiga kali ulangan. Data yang didapatkan dalam proses pengukuran ini di gunakan sebagai pembanding dengan data dari pengukuran curah hujan menggunakan alat tipe observatorium yang belum dimodifikasi.

Langkah Pengujian:

a. Siapkan gelas ukur

b. Buka Kran sampai air habis

c. Catat waktu dan volume pengukuran.

3.Pengujian dengan Penakar curah hujan tipe observatorium sebelum dimodifikasi

Setelah pengukuran pertama selesai maka pengukuran kedua dilakukan dengan tujuan untuk membandingkan waktu penakaran curah hujan sebelum dan sesudah dimodifikasi.

Langkah pengujian:

1. Turunkan alat dari tiang

2. Buka corong

3. Angkat tabung penampung curah hujan

4. Tuang pada gelas ukur sampai air habis

5. Catat waktu dan volume pengukuran

\section{Analisa Data}

Data yang diperoleh akan di analisa secara Deskriptif dengan melihat tampilan grafik-grafik untuk mengetahui 
pengaruh alat yang sudah dimodifikasi dengan yang belum dimodifikasi.

\section{Skema Pengujian}

Adapun skema pengujian dapat dilihat pada gambar dibawah ini:

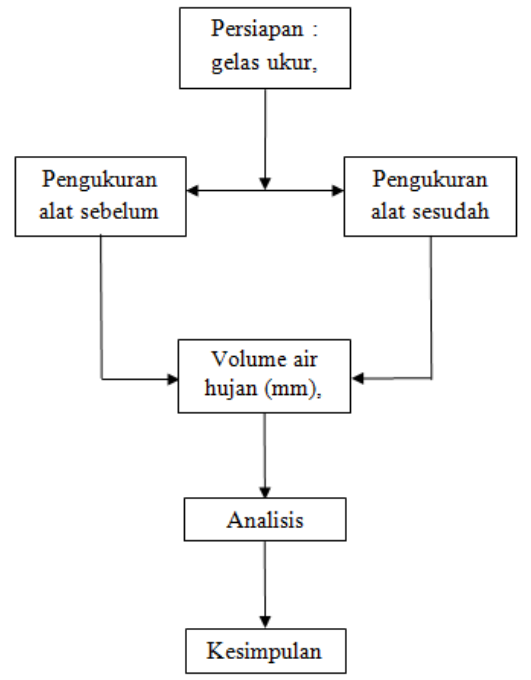

Gambar 3. Skema Pengujian Alat penakar Curah Hujan Tipe

Observatorium (OBS)

\section{HASIL DAN PEMBAHASAN}

Pengujian Penakar Curah Hujan tipe Observatorium (OBS) sebelum penambahan kran

Adapun

langkah-langkah

pengujian penakar curah hujan tipe Observatorium sebelum penambahan kran adalah sebagai berikut:

a. Langkah pertama pengukuran curah hujan tipe Observatorium manual adalah mengangkat corong penakar curah hujan.

b. Langkah kedua proses mengambilan jerigen penakar curah hujan tipe Observatorium.

c. Langkah ketiga mengangkat jerigen penampung curah hujan dari dalam tabung penakar curah hujan tipe Observatorium.

d. Langkah keempat menuangkan curah hujan dari dalam jerigen ke gelas ukur.
Hasil Pengujian Penakar Curah Hujan tipe Obsevatorium (OBS) manual

Tabel 1. Hasil pengujian penakar curah hujan tipe observatorium (OBS) manual

\begin{tabular}{|c|c|c|c|c|}
\hline \multirow{2}{*}{$\begin{array}{c}\text { Volume } \\
\text { curah } \\
\text { hujan } \\
(\mathrm{mm})\end{array}$} & \multicolumn{3}{|c|}{ Waktu (detik) } & \multirow{2}{*}{$\begin{array}{c}\text { Rata- } \\
\text { rata }\end{array}$} \\
\hline & U1 & U2 & U3 & \\
\hline 10 & 100 & 114 & 115 & 109,7 \\
\hline 25 & 230 & 243 & 258 & 243,7 \\
\hline 50 & 420 & 440 & 432 & 430,7 \\
\hline
\end{tabular}

Pengujian Penakar Curah Hujan tipe Observatorium (OBS) yang Sudah Dimodifikasi dengan Tambahan Kran

Langkah pengujian curah hujan cukup membuka kran lalu mengukur curah hujan dengan gelas ukur

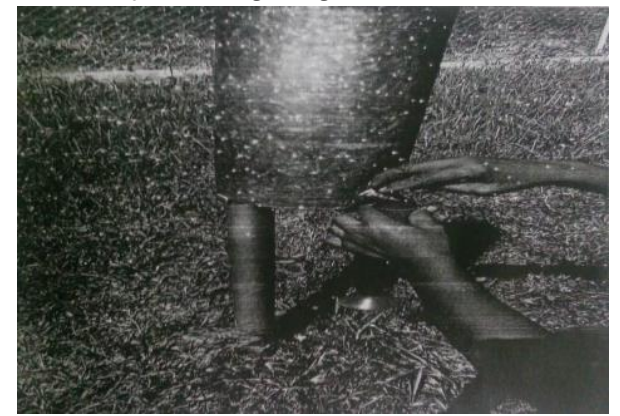

Gambar 4. Penakaran curah hujan menggunakan penakar curah hujan tipe Observatorium yang sudah dimodifikasi dengan tambahan kran.

Hasil Pengujian Penakar Curah Hujan tipe Observatorium (OBS) yang Sudah Dimodifikasi dengan Tambahan Kran

Tabel 2. Hasil pengujian penakar curah hujan tipe Observatorium yang sudah dimodifikasi dengan tambahan kran

\begin{tabular}{|c|c|c|c|c|}
\hline Volume & \multicolumn{2}{|c|}{ Waktu (detik) } & \multirow{2}{*}{$\begin{array}{c}\text { Rata- } \\
\text { curah } \\
\text { hujan } \\
\text { (mm) }\end{array}$} & \multicolumn{2}{|c|}{ U2 } & U2 & U3 & \\
\hline 10 & 68 & 68 & 69 & 68,3 \\
\hline 25 & 135 & 135 & 135 & 135,0 \\
\hline 50 & 268 & 268 & 268 & 268,0 \\
\hline
\end{tabular}


Analisa Hasil Pengujian Penakar Curah Hujan tipe Observatorium (OBS) Sesudah Dimodifikasi

Pengujian dilakukan sebanyak 3 (tiga) kali ulangan dengan volume curah hujan yang bervariasi yaitu curah hujan $10 \mathrm{~mm}, 25 \mathrm{~mm}$, dan $50 \mathrm{~mm}$. Dari ketiga kali pengujian dihasilkan data rata-rata waktu $10 \mathrm{~mm}=68,3$ detik, $25 \mathrm{~mm}=135,0$ detik, $50 \mathrm{~mm}=268,0$ detik.

Analisa Hasil Pengujian Penakar Curah Hujan tipe Observatorium (OBS) yang Sudah Dimodifikasi dengan Tambahan Kran

Pengujian dilakukan 3 (tiga) kali ulangan sama halnya dengan pengujian Penakar Curah Hujan tipe Observatorium (OBS) manual dengan volume curah hujan yang sama. Dari hasil pengujian didapatkan data, untuk volume curah hujan $10 \mathrm{~mm}$ dari ketiga kali pengujian dihasilkan waktu rata-rata $=68,3$ detik, volume curah hujan $25 \mathrm{~mm}$ waktu yangdihasilkan rata-rata $=135$ detik, dan volume curah hujan $50 \mathrm{~mm}=268$ detik. Dari hasil pengujian dan analisa data perbedaan waktu dalam penakaran curah hujan menunjukan waktu yang sangat signifikan, hal ini dapat dilihat melalui tampilan grafik dibawah ini.

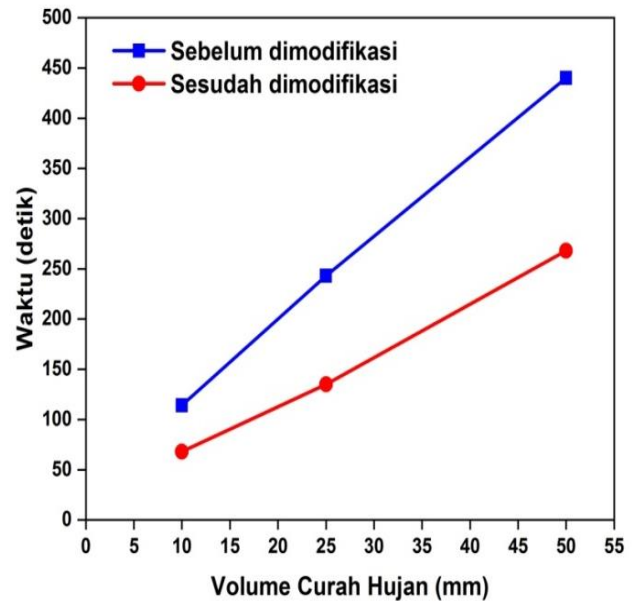

Gambar 5. Grafik hubungan antara waktu dengan volume curah hujan
Analisa Presentase Penurunan Waktu Pengujian Penakar Curah Hujan tipe Observatorium (OBS) yang Belum dengan yang Sudah Dimodifikasi dengan Tambahan Kran

Tabel 3. Rata-rata waktu penakaran curah hujan tipe Observatorium (OBS) sebelum dimodifikasi

\begin{tabular}{|c|c|}
\hline $\begin{array}{c}\text { Volume curah } \\
\text { hujan (mm) }\end{array}$ & $\begin{array}{c}\text { Rata-rata } \\
\text { waktu (detik) }\end{array}$ \\
\hline 10 & 110 \\
\hline 25 & 243 \\
\hline 50 & 431 \\
\hline
\end{tabular}

Tabel 4. Rata-rata waktu penakaran curah hujan tipe observatorium (OBS) yang sudah dimodifikasi dengan tambahan kran

\begin{tabular}{|c|c|}
\hline $\begin{array}{c}\text { Volume curah } \\
\text { hujan (mm) }\end{array}$ & $\begin{array}{c}\text { Rata-rata } \\
\text { waktu (detik) }\end{array}$ \\
\hline 10 & 68 \\
\hline 25 & 135 \\
\hline 50 & 268 \\
\hline
\end{tabular}

Tabel 5. Presentase waktu penakaran curah hujan tipe observatorium (OBS) sebelum dan sesudah dimodifikasi dengan tambahan kran serta presentase penurunan waktu

\begin{tabular}{|c|c|c|}
\hline $\begin{array}{c}\text { Volum } \\
\mathbf{e} \\
\text { Curah } \\
\text { Hujan } \\
(\mathbf{m m})\end{array}$ & $\begin{array}{c}\text { Rata-rata } \\
\text { persentas } \\
\text { e waktu } \\
(\%)\end{array}$ & $\begin{array}{c}\text { Rata-rata } \\
\text { persentas } \\
\mathbf{e} \\
\text { penuruna } \\
\text { n waktu } \\
(\%)\end{array}$ \\
\hline 10 & 61,81 & 38,19 \\
\hline 25 & 55,55 & 44,45 \\
\hline 50 & 62,18 & 37,82 \\
\hline
\end{tabular}

Persentase Waktu

$=\frac{\text { Rata }- \text { rata waktu sesudah dimodifikasi }}{\text { Rata }- \text { rata waktu sebelum dimodifikasi }} \times 100 \%$

Persentase Penurunan Waktu

$=100 \%-$ Persentase waktu $\%$ 


\section{PENUTUP}

\section{Kesimpulan}

Dari eksperimen, pengujian, analisa, dan diskusi dapat ditarik beberapa kesimpulan tentang pengaruh pemasangan kran pada penakar curah hujan tipe observatorium (OBS):

1. Penurunan waktu:

a. Penakaran curah hujan volume $10 \mathrm{~mm}$, mengalami penurunan waktu yang cukup baik dengan menunjukan persentase penurunan sebesar $38,19 \%$.

b. Penakaran curah hujan volume $25 \mathrm{~mm}$, mengalami penurunan waktu yang cukup baik dengan menunjukan persentase penurunan sebesar $44,45 \%$.

c. Penakaran curah hujan volume $50 \mathrm{~mm}$, mengalami penurunan waktu yang cukup baik dengan menunjukan persentase penurunan sebesar $37,82 \%$.

2. Hasil penakaran curah hujan menggunakan penakar curah hujan tipe observatorium (OBS) yang dimodifikasi dengan tambahan kran hasil pengukuran lebih valid karena volume curah hujan dapat berhasil ditakar semua dibandingkn dengan penakar curah hujan tipe OBS yang masih manual dikaenakan sering tumpah saat menuangkan air curah hujan dalam jerigen ke gelas ukur.

\section{Saran}

Adapun saran dari pengujian yang dapat dilakukan untuk perkembangan riset selanjutnya adalah sebagai berikut:

1. Untuk selanjutnya dapat membuat penakar curah hujan tipe obseratorium (OBS) dengan penambahan diameter kran yang lebih besar dan menggunakan pelat stanlis agar penakaran lebih efektif dan valid.
2. Setelah selesai pengukuran curah hujan dipastikan kran tertutup rapat untuk menghindari kebocoran.

\section{DAFTAR PUSTAKA}

Lakitan, Benyamin. 1994. Dasar-dasar klimatologi. PT Rajagrafindo persada. Depok, Jawa Barat.

Luh, Sami Asih, I Wayan Muderawati, dkk. 2013. Analisis Standar Laboratorium Kimia dan Efektivitasnya terhadap capaian kompetensi Adaptip di SMK Negeri 2 Negara. E Jurnal Program pasca sarjana Universitas pendidikan Ganesha, Program study IPA. Vol. 3. 2013

Nasir, A.N dan S. Effendy. 1999. Konsep Neraca Air Untuk Penentuan Pola Tanam. Kapita Selekta Agroklimatologi Jurusan Geofisika dan Meteorologi Fakultas Matematika dan IPA. Institut Pertanian Bogor.

Prof. Dr. Ir. Arifin, MS. 2010. Modul klimatologi. Fakultas pertanian: Universitas Brawijaya. Malang

Tjasyono, Bayon. 2004. Klimatologi. Bandung: Institut Teknologi Bandung ITB. 